\title{
Thermal interference of engineering construction with permafrost ground as bottom
}

\author{
Ulyana Shastunova ${ }^{1, *}$ and Pavel Michailov ${ }^{1}$ \\ ${ }^{1}$ TyumenState University, Volodarskogo Str., 6, Tyumen, 625003, Russia
}

\begin{abstract}
We provided laboratory results of temperature fields dynamic in permafrost ground under engineering construction which is modelling tank with oil. We wrote down non-stationary thermophysical model in the system "tank - bottom" considering mass-transfer of pore wetness. Calculated and experimental data approbation was made; close agreement of thawing halo location was shown with consideration of heat convection, associated with wetness migration in the area of thawed ground.
\end{abstract}

\section{Introduction}

According to the 1stprinciple of permafrost ground constructing it is important to keep the ground permafrost not only in the constructing process, but during all operational period.

Temperature stabilization of ground is used quite often for loss prevention of base loadbearing capacity. Using of this system leads to material cost increase of construction. During the process of operating the risks of no repairable break down initiation is getting higher. It can lead to further thawing which may become a cause of destruction.

Thus, special topicality has a research of heat and mass transfer in permafrost grounds and their compatibility with engineering constructions. It is important to meet the challenge of «surroundings - construction - ground».

\section{Topicality}

Most of the modern models of heat and mass transfer [Doldih and others, 2015], [Reshetnikov, 2002], [Gorelik J.B., Kolunin V.S., Reshetnikov A.K., 1999] in permafrost ground do not take into account all significant factors which are wind, solar radiation, operating mode of engineering construction, all layers of bottom, permafrost rock parameters in bottom. Thermal interplay of ground and construction, heat convection related to pore wetness migration are also not taken into account.

Low knowledge of noted factors in prediction calculations correctness does not guarantee the usage of a building under the 1st constructing principle on permafrost grounds. Thus, the priority is solving simultaneous equations of heat and mass transfer in the «engineering construction - bottom» system which takes into account main and significant factors. The goal is experimental research of thawing and freezing processes of

*Corresponding author: ulyakuz 85@mail.ru 
permafrost ground in order to their further correlation with appropriateness of provided physico-mathematical model. In this investigation we chose steel tank as a researching engineering construction.

\section{Experimental facility}

In department of Mechanics of multiple systems of Tyumen State University we created experimental facility in the development laboratory on research of permafrost grounds and engineering constructions cooperation to study process of heat and mass transfer in permafrost ground. General scheme of facility is shown in figure 1.

Experimental facility consists of the following items: climatic cell (2), container (16), heat -insulation (12), model of vertical steel tank (9), pump (6), heating system $(4,5)$, system of cooling tubes $(7,8,15)$, cryostat (3) and automatic temperature-measuring system in ground and tank $(1,13)$.

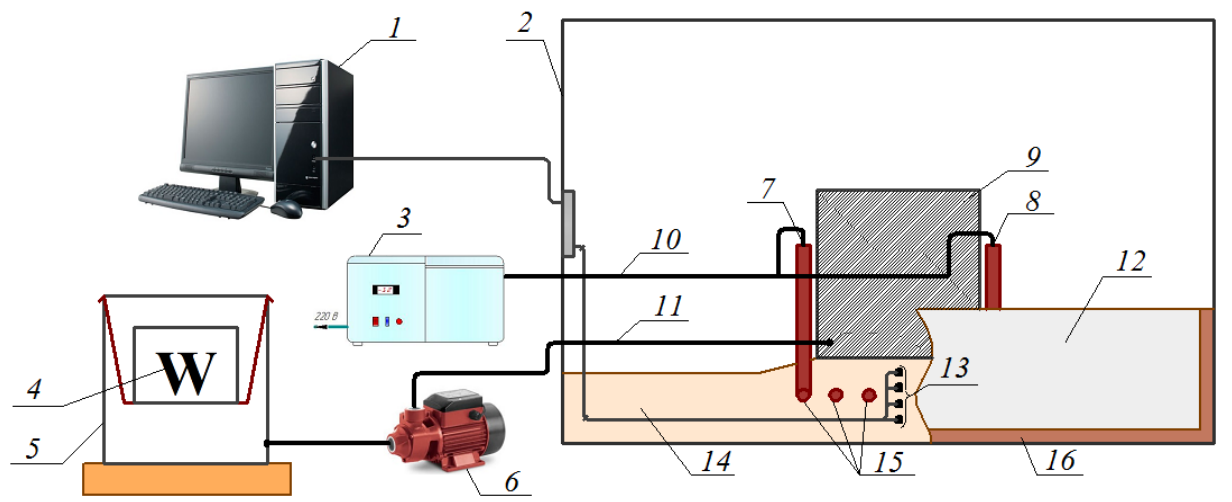

Fig. 1.Scheme of experimental facility: 1 - personal computer; 2 - climatic cell; 3 - cryostat; 4 heating unit; 5 - heating oil tank; 6 - pump; 7 - entrance for system of cooling tubes; 8 - exit for system of cooling tubes; 9 - model of vertical steel tank; 10 - line for pumping of refrigerant; 11 line for pumping of heat transfer fluid; 12 - heat -insulating of working area; 13 - temperature sensor; 14 - ground; 15 - system of cooling tubes; 16 -container.

Container to limit ground working area is isolated by expandable polystyrene. That allows to consider heat flow rate through freezing unit wall to be equal to zero.

The ground we used in our research is a sand clay. Thermal-physical properties of the ground are shown in the table 1.

Table 1.Thermal-physical properties of the ground.

\begin{tabular}{|c|c|c|}
\hline \multicolumn{2}{|l|}{ Density, $\mathrm{kg} / \mathrm{m} 3$} & 2083 \\
\hline \multicolumn{2}{|l|}{ Wetness, $\%$} & 21 \\
\hline \multirow{2}{*}{ Thermal conductivity, $\mathrm{W} /(\mathrm{m} \cdot \mathrm{K})$} & permafrost ground & 3.13 \\
\hline & Thawed ground & 2.38 \\
\hline \multirow{2}{*}{ Specific thermal capacity, $\mathrm{kJ} /(\mathrm{kg} \cdot \mathrm{K})$} & permafrost ground & 0.95 \\
\hline & thawed ground & 1.06 \\
\hline
\end{tabular}

In accordance with Russian SrandardGOST5180-84 ground wetness was found by the method of drying-out till fixed-mass.

Allocation of ground wetness through depth of cover is shown in the table 2. 
Table 2.Measuring results of ground wetness.

\begin{tabular}{|c|c|c|}
\hline \multirow{2}{*}{ Depth, тт мм } & \multicolumn{2}{|c|}{ Wetness, \% } \\
\cline { 2 - 3 } & permafrost ground & thawing ground \\
\hline 0 & 12.50 & 17.86 \\
\hline 40 & 12.61 & 18.77 \\
\hline 80 & 13.87 & 19.62 \\
\hline 120 & 15.79 & 20.11 \\
\hline 160 & 16.76 & 20.76 \\
\hline
\end{tabular}

Automated system of temperature monitoring consists of digital temperature sensors DS18B20, personal computer, 1-Wire network adapterCOMand stabilized power supply.

For work with sensors DS18B20 we set up a program to look after and save temperature for each sensor [Shastunova, Yanbikova, 2015].

The total number of temperature sensors we used is 56,11 of them are installed in the container to control oil temperature, gas space and container walls on various height. 45 are installed in the research ground.

As long as our problem is radio symmetrical the sensors in the ground a replaced radially.In order to low error measurement cause of temperature sensors displacement the bar to fix them was used.

Heat of heat-transfer fluid (oil) is made according to principle of coaxial vessels: there is a heating unit inside a water container, which is inside the oil tank. While experimentation circulate oil is made, which helps to keep temperature constant.

Initial temperature of ground while experimentation is the same in every point and equal to the temperature of freezing unit, mines $10{ }^{\circ} \mathrm{C}$. Temperature of load oil is $50 \div 57^{\circ} \mathrm{C}$. The experimentation leads during 9 hours 30 minutes. According to the sensors value temperature fields were made in ground in different moments (Fig. 2-5).

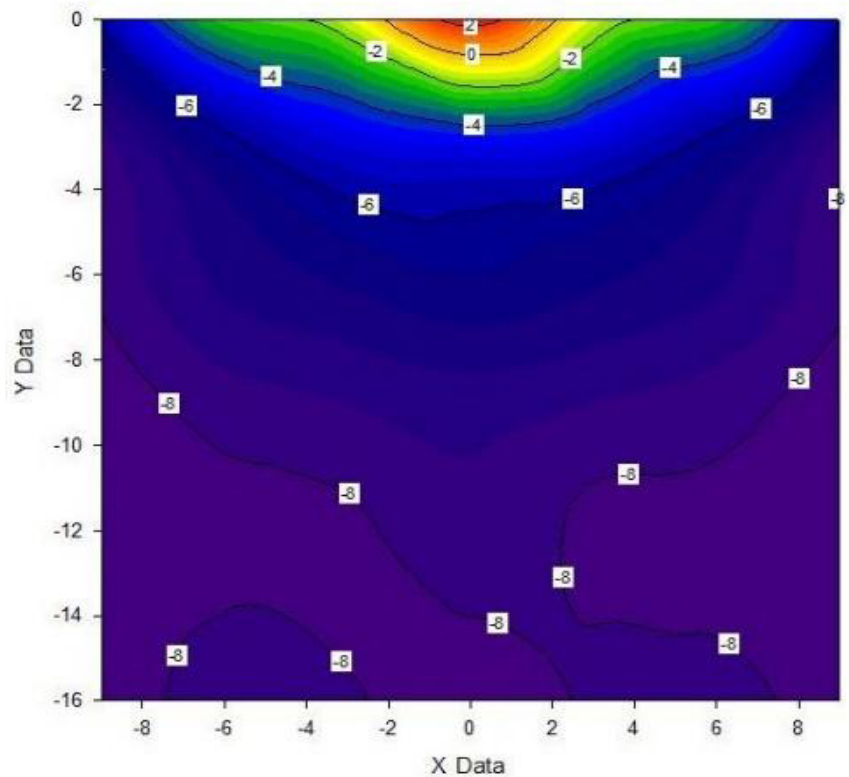

Fig. 2. Ground temperature field in $\mathrm{t}=10$ minutes after turning on the heat. 


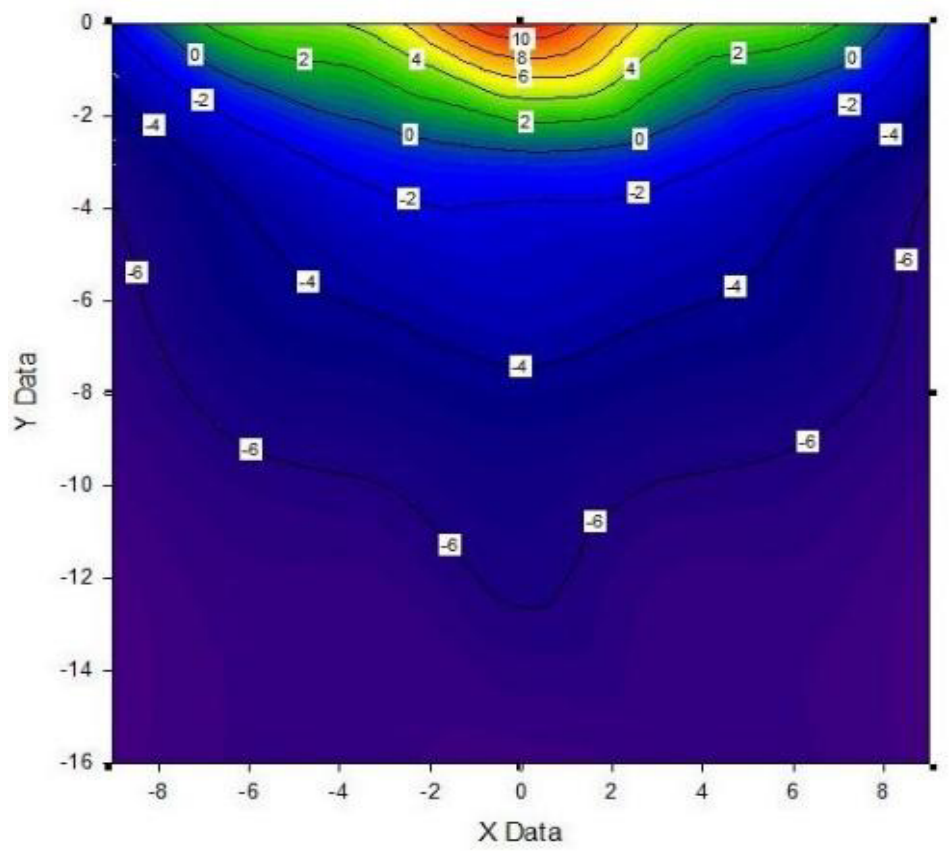

Fig. 3. Ground temperature field in $t=1.5$ hours after turning on the heat.

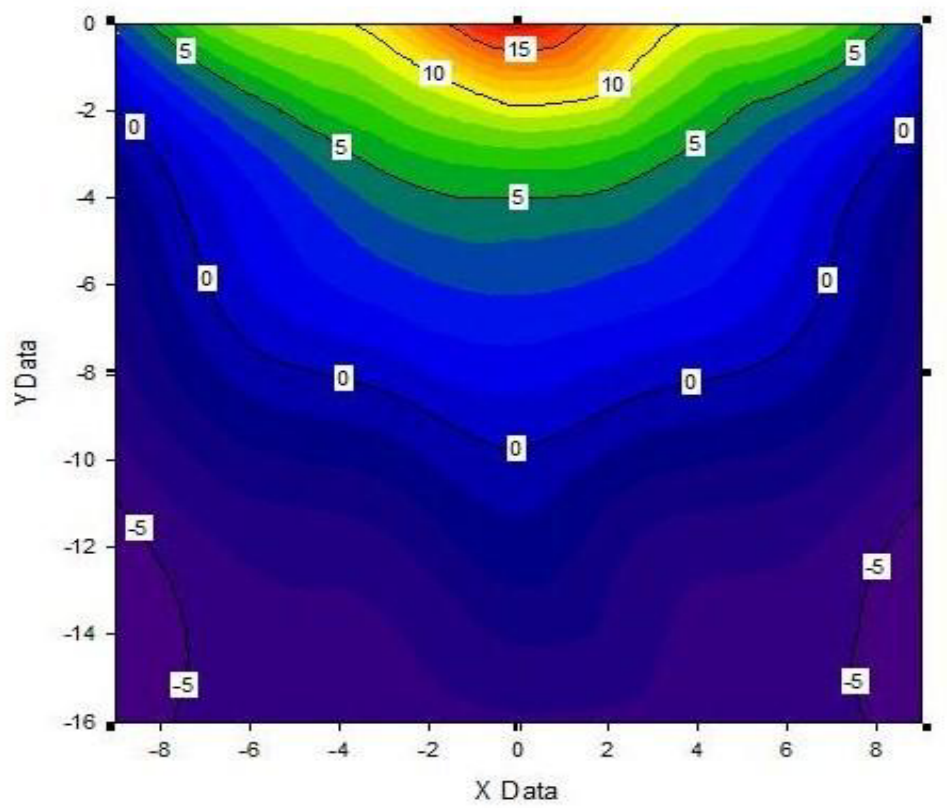

Fig. 4. Ground temperature field in $t=4.5$ hours after turning on the heat. 


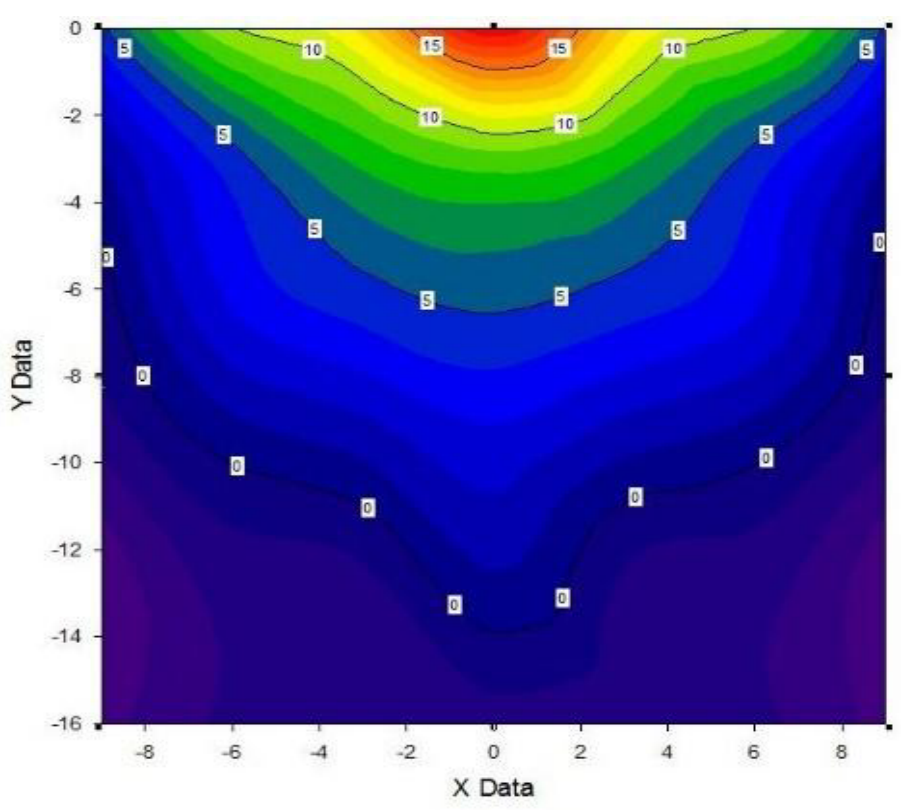

Fig.5.Ground temperature field in $\mathrm{t}=9$ hours after turning on the heat.

\section{Experimental data discussion}

As could be expected temperature distribution and thawing front (isotherm $\mathrm{T}=0^{\circ} \mathrm{C}$ ) are almost symmetrical towards vertical axis, which goes through tank centre. A small deviation is attributable to certain experimental errors: non-uniform ground, slight displacement of temperature sensors during preparation and experimentation, sensors parameter spread and others.

However in time changing of thawing front shape is happening unexpected. At the beginning as it must be the front has a shape of oval with smooth steady changing of curvature radius. But after 1.5 hour the outgrowth ("tongue") began to develop in the front centre and grew in time. At the end of heating the front has a clear central zone, moving fare on in comparison with side zones [Kislitsin, Shastunova, 2015].

We can explain it like that: as long as water volume is smaller than ice volume pores appear in thaw ground. Thawing water is moving down through pores to the thawing center. Heatconvection appears, thawingspeedrises.

Also during experimentation we found relationship between gas space temperature changing (hereinafter $-\mathrm{Tg}$ ), and hot heat transfer fluid (hereinafter $-\mathrm{T}_{1}$ ) intime[Shastunova, Dmitrievskaya, 2016]. ExperimentalresultsareshowninFig.6a, b. 


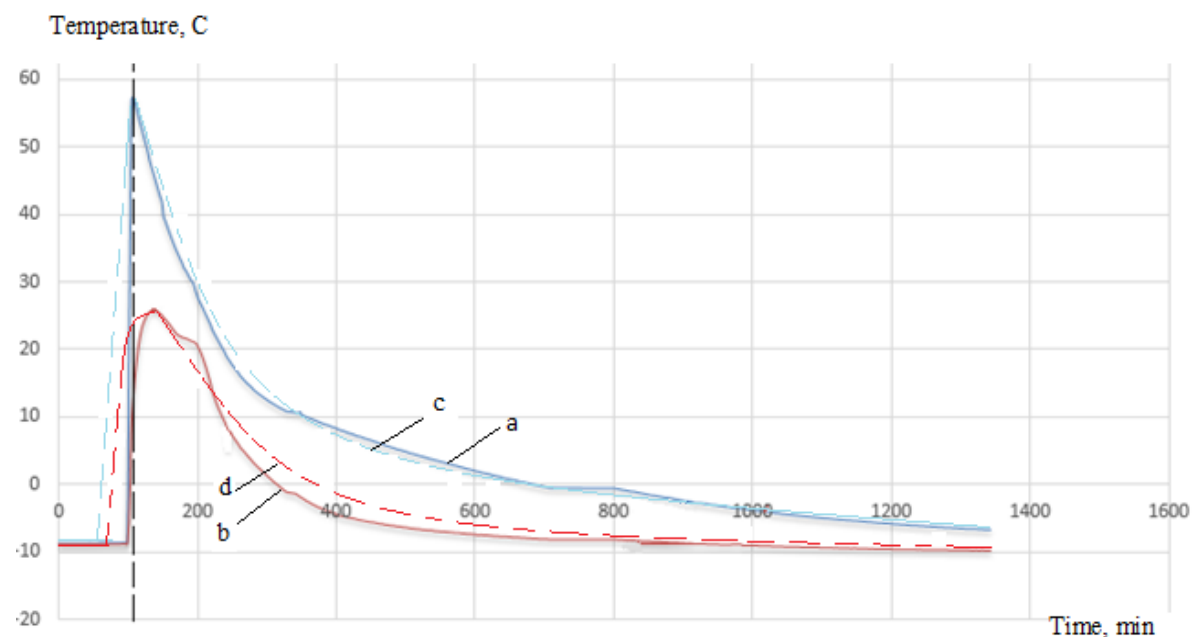

Fig. 6.Changing of temperature condition in tank in time: $a, b$ (full line graph) - experimental curves; $\mathrm{c}, \mathrm{d}$ (dotted graph) - numerical solution; a,c - temperature curve of oil in tank; b, d - temperature curve of gas space.

Vertical dash-linemarks splitting of two experimentation conditions: piping condition is on the left of the line, storage condition of heat transfer is on the right of the line.

Temperature of surrounding air in climate chamber was equal to mines $10{ }^{\circ} \mathrm{C}$. In the beginning of piping $\mathrm{T}_{\mathrm{h}}$ roesand heated the walls of cold metal tank, it reached $57^{\circ} \mathrm{C}-$ the level of temperature in which the oil tank was heated. According to exponential dependence $T_{1}$ is getting lower in the storage condition.

As for gas space: $\mathrm{T}_{\mathrm{g}}$ is also rises in piping condition. However when the oil reached its maximum temperature gas space temperature was increased further during 15-20 minutes in storage condition. When the oil temperature reached its maximum $24^{\circ} \mathrm{C}$ it started to decrease. We can explain it by complicated gas convective flow inzone of gas space inside the tank.

\section{Non-stationary thermophysicalmodel in the system «tank - bottom»}

Interaction of construction with permafrost groundis represented by complex system of the rmophysicsnon linear differential equation. In this work [Kislitsin, Shastunova, 2015] the authors found an approximate quasi-stationary solution of Stephen'stwo-dimensional problem in cylindrical coordinates $\mathrm{r}$, $\mathrm{x}$. Not only including pore wetness transfer, but also without it.

The model under the discussion could be used for projecting and prediction of ground thermal and wetness conditions while using tank battery in complicated geotechnical conditions for thawing halo appraisement and base load-bearing capacity.

Computer modelling based on numerical calculation of simultaneous equations. This simultaneous equations consist of heat-balance equations for gas and oil phase, equation for flow-rate of thermal transfer fluid, equation for thermal transfer in two-dimensional coordinates including phase change and pore wetness migration.

Let us write down thermo physical model. We shall call gas, fluid and ground system components by $\mathrm{g}, \mathrm{l}, \mathrm{s}$ respectively. 


$$
\left\{\begin{array}{l}
\frac{\partial\left(C_{g} \cdot \rho_{g} \cdot \pi R^{2} \cdot(H-h) \cdot\left(T_{g}-T_{0}\right)\right)}{\partial t}=-C_{g} \cdot \rho_{g} \cdot \pi R^{2} \cdot\left(T_{g}-T_{0}\right) \cdot \frac{\partial(H-h)}{\partial t}+k_{g o l} \cdot\left(T_{g}-T_{0}\right) \cdot \pi R^{2}+ \\
+k_{g o 2} \cdot\left(T_{g}-T_{0}\right) \cdot 2 \pi R \cdot(H-h)-\alpha_{g l} \cdot\left(T_{g}-T_{l}\right) \cdot \pi R^{2} \\
\frac{\partial\left(C_{l} \cdot \rho_{l} \cdot \pi R^{2} \cdot h \cdot\left(T_{l}-T_{0}\right)\right)}{\partial t}=C_{l} \cdot \rho_{l} \cdot \pi R^{2} \cdot\left(T_{l o}-T_{l}\right) \cdot \frac{\partial h}{\partial t}+k_{l o} \cdot\left(T_{l}-T_{0}\right) \cdot 2 \pi R h+ \\
+k_{l s} \cdot\left(T_{l}-T_{s}\right) \cdot \pi R^{2}+\alpha_{\mathrm{lg}} \cdot\left(T_{l}-T_{g}\right) \cdot \pi R^{2} \\
\frac{\partial T_{s}}{\partial t}=a_{s} \cdot\left(\frac{1}{r} \cdot \frac{\partial}{\partial r} \cdot\left(r \cdot \frac{\partial T_{s}}{\partial r}\right)+\frac{\partial^{2} T_{s}}{\partial z^{2}}\right)+\vartheta_{r} \cdot \frac{\partial T_{s}}{\partial r}+\vartheta_{z}\left(\frac{\partial T_{s}}{\partial z}\right) \\
\vartheta_{r}=-K \cdot \frac{\partial w}{\partial r}, \vartheta_{z}=-K \cdot \frac{\partial w}{\partial z} \\
G=\pi R^{2} \cdot \frac{d h}{d t}
\end{array}\right.
$$

Where $\mathrm{T}_{0}$ - surrounding temperature, $\mathrm{K} ; T_{l o}$ - upstream temperature of heat transfer fluid under constant flow rate $G, K ; k_{g o 1}$ - heat transfer coefficient through tank top, $W /\left(m^{2} \cdot K\right)$; $k_{g o 2}$ - heat transfer coefficient through tank wall to the zone of gas space, $W /\left(m^{2} \cdot K\right) ; \alpha_{g l}$ and $\alpha_{\mathrm{lg}}$ - heat transfer coefficient from steam-and-gas mixture to «hot» heat transfer fluid and back, $W /\left(m^{2} \cdot K\right) ; k_{l o}$ - heat transfer coefficient through side wall of tank to the zone of liquid space $W /\left(m^{2} \cdot K\right) ; k_{l s}$ - heat transfer coefficient through the bottom from hot heat transfer to tank bottom $W /\left(m^{2} \cdot K\right) ; C_{g, l, s}$ and $\rho_{g, l, s}$ - heat capacity and density of steamand-gas mixture, heat transfer and ground, $J /(\mathrm{kg} \cdot K), \mathrm{m} ; R, H$ - radius and height of

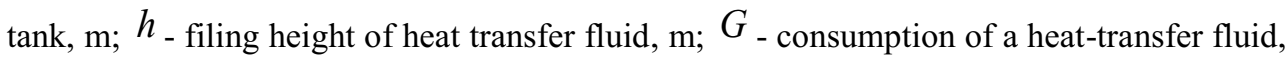
$\mathrm{m}^{3} / s, a_{s}$ - thermal conductivity coefficient of the ground, $\mathrm{m} / \mathrm{s}^{2}, \vartheta_{r_{\mathbf{\Lambda}}} \vartheta_{z}$ - filtration velocity of pore wetness, $\mathrm{K}-$ isothermal coefficient of hydraulic conductivity, $\mathrm{m} / \mathrm{s}^{2}, w$ height wetness.

We gave all the details how we count heat transfer coefficient in [Bakhmat, Kislitsin, Shastunova, 2011], [Gishkelyuk, Stanislovskaya, Evlanov, 2015], [Shastunova, Yanbikova, 2015].

Finite-difference approximation of the system (1) was calculated using implicit schema [Paskonov, Polezhaev, Chudov, 1986] with following starting and bounder conditions:

Starting conditions:

Where:

$$
t=0 ; h=0, T_{g}=T_{0} ; T_{l}=T_{l o} ; J=k_{l s} \cdot\left(T_{l}-T_{s}\right) \cdot \pi R^{2}=0 ;
$$

For $z=0 ; T_{s}=T_{0}$

Border conditions: 


$$
\begin{aligned}
& z>0, T_{s}=T_{s}(z) \\
& z=L, T_{s}=T(L)=\mathrm{const} \\
& J=k_{l s} \cdot \pi R^{2} \cdot\left(T_{l}-T_{s}\right)=\left.\lambda \frac{\partial T_{s}}{\partial z}\right|_{z=0}
\end{aligned}
$$

\section{Numerical calculation discussion}

According to the numerical calculation results and experimental research we represented graphs which show dynamic pattern of permafrost ground thawing haloin Fig. 7. As it obvious, numerical calculation of non-stationary thermo physical model in the system «tank - bottom» including influence of pore wetness migration gives us exact match with experimental data than excluding it.

Also we plotted of temperature changing variance of gas space and hot heat transfer fluid. Good agreement of experimental data and numerical calculation is shown in Fig. 6.

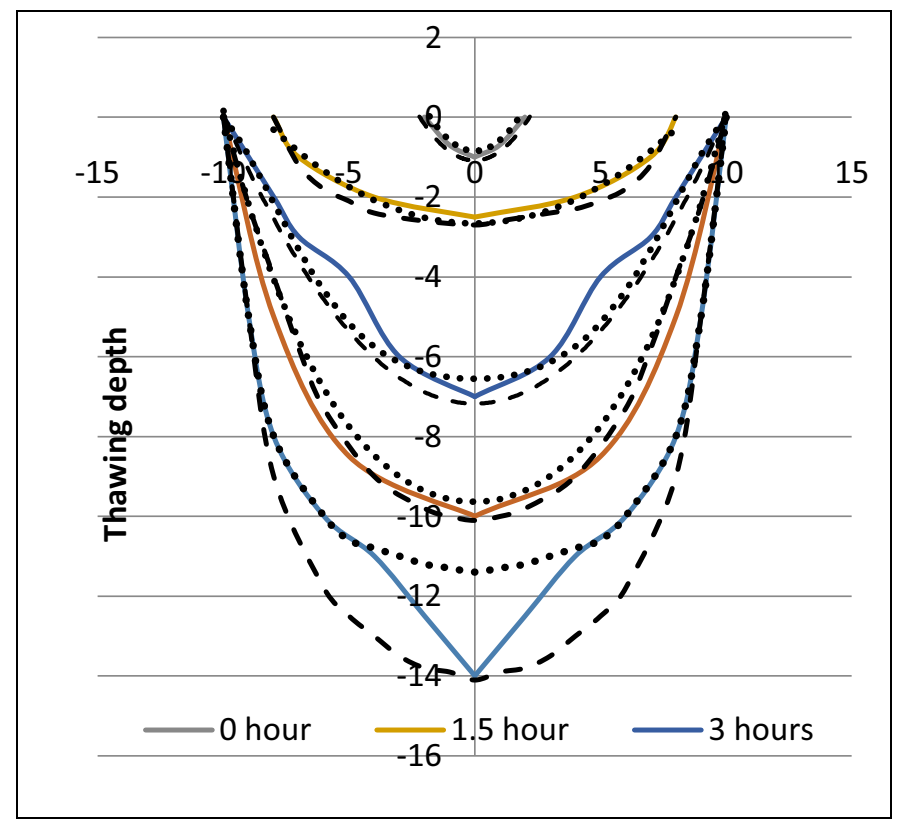

Fig.7.Dynamic pattern of permafrost ground thawing halo. Full line - experimental value. ---- (dotted line) - numerical calculation including convection. ${ }^{* *}$ - numerical calculation excluding convection.

\section{Conclusion}

It is deduced from experiments pore wetness migration has a strong effect on ground thawing halo form and speed while thermal interference in the system «tank - bottom».

We madenon-stationary thermo physical model taking into account pore wetness migration. Numerical calculation gives us satisfactory fit with experimental data. 
The model we recommend could be used for calculation of permafrost ground temperature schedule in natural conditions. That helps to predict processes in permafrost ground if the system of temperature stabilization would break down.

The model under the discussion could be also accommodated for prediction of permafrost ground thermal and wetness conditions for other engineering constructions. For instance: pipelines, buildings, fuel and energy complex enterprises.

\section{Acknowledgments}

The job is made with financial support from Russian Foundation for Basic Research № 1638-00461

\section{References}

1. G. Dolgikh, G. Anikin, I. Rilo, K. Spasennikova,Kriosferazemli (Cryosphere of the Earth), 1, 70-77 (2015)

2. Reshetnikov, Computational modelling of heat - mass transfer and deformation processes in permafrost grounds: Ph.D. Thesis, Tyumen (2002)

3. G. Bakhmat, A. Kislitsyn, U. Shastunova,Thermal conditioncalculation method of vertical steel tank PBC in winter time while in operation (City-Press, Tyumen, 2011)

4. J.B.Gorelik, V.S.Kolunin, A.K.Reshetnikov, Advances in cold-region thermal engineering and sciences, 6, 465-474 (1999).

5. U.Shastunova, Yu.Yanbikova, Naukasegodnya (Science today): Collection of scientific papers adapted from International research and practice conference: in four parts, 1,80$83(2015)$

6. A.Kislitsin, U.Shastunova, Tyumen State University Herald. Physical and Mathematical Modeling. Oil, Gas, Energy, 1,15-25 (2015)

7. U.Shastunova,D.Dmitrievskaya, Tyumen State University Herald. Physical and Mathematical Modeling. Oil, Gas, Energy, 2, 24-30 (2016)

8. I.Gishkelyuk, Yu.Stanislavskaya, D.Evlanov,Science\& Technologies: Oil and Oil Products Pipeline Transportation, 1(17), 20-25 (2015)

9. V.Paskonov, V.Polezharev, L.Chudov,Computational modelling of heat-mass transfer processes (Nauka (Science), Moscow, 1994) 